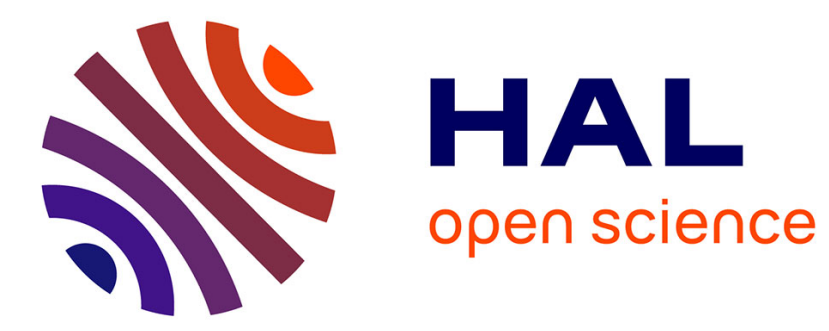

\title{
Spectroscopy of neutron-deficient nuclei around ${ }^{36} \mathbf{C a}$
}

A. Bürger, M. Stanoiu, F. Azaiez, Zs. Dombrádi, A. Algora, A. Al-Khatib, B.

Bastin, G. Benzoni, R. Borcea, Ch. Bourgeois, et al.

\section{To cite this version:}

A. Bürger, M. Stanoiu, F. Azaiez, Zs. Dombrádi, A. Algora, et al.. Spectroscopy of neutron-deficient nuclei around ${ }^{36}$ Ca. S.V. Harissopulos, P. Demetriou, E. Julin. Frontiers in Nuclear Structure, Astrophysics, and Reactions - FINUSTAR, Sep 2005, Isle of Kos, Greece. AIP Press, 831 (831), pp.418-420, 2006, AIP Conference Proceedings. 10.1063/1.2200968 . in2p3-00087237

\section{HAL Id: in2p3-00087237 https://hal.in2p3.fr/in2p3-00087237}

Submitted on 5 Jan 2007

HAL is a multi-disciplinary open access archive for the deposit and dissemination of scientific research documents, whether they are published or not. The documents may come from teaching and research institutions in France or abroad, or from public or private research centers.
L'archive ouverte pluridisciplinaire HAL, est destinée au dépôt et à la diffusion de documents scientifiques de niveau recherche, publiés ou non, émanant des établissements d'enseignement et de recherche français ou étrangers, des laboratoires publics ou privés. 


\title{
Spectroscopy of neutron-deficient nuclei around ${ }^{36} \mathrm{Ca}$
}

A. Bürger ${ }^{*, \dagger}$, M. Stanoiu ${ }^{* *, \dagger}$, F. Azaiez ${ }^{* *}$, Zs. Dombrádi ${ }^{\S}$, A. Algora ${ }^{\S}$, A. Al-Khatib*, B. Bastin ${ }^{\mathbb{I}}$, G. Benzonill, R. Borcea ${ }^{\dagger \dagger}$, Ch. Bourgeois**, P. Bringel* , E. Clément ${ }^{\dagger}$, J.-C. Dalouzy ${ }^{\ddagger}$, Z. Dlouhý§§ , A. Drouart ${ }^{\dagger}$, C. Engelhardt*, S. Franchoo**, Zs. Fülöp ${ }^{\S}$, A. Görgen ${ }^{\dagger}$, S. Grévy ${ }^{\ddagger}$, H. Hübel*, F. Ibrahim**, W. Korten ${ }^{\dagger}$, J. Mrázek ${ }^{\S \S}$, A. Navin ${ }^{*}$, C. Timis ${ }^{\text {IIII }}$, F. Rotaru ${ }^{\dagger \dagger}$, P. Roussel-Chomaz ${ }^{\ddagger}$, M.-G. Saint-Laurent ${ }^{\ddagger}$, G. Sletten ${ }^{* * *}$, D. Sohler ${ }^{\S}$, O. Sorlin ${ }^{\dagger \dagger}$, Ch. Theisen ${ }^{\dagger}$, D. Verney** and S. Williams ${ }^{\text {ITI }}$

\author{
${ }^{*}$ Helmholtz-Institut für Strahlen- und Kernphysik, Univ. Bonn, Germany \\ ${ }^{\dagger}$ DAPNIA/SPhN, CEA Saclay, France \\ ** Institut de Physique Nucléaire, IN2P3-CNRS, Orsay, France \\ ${ }^{\ddagger}$ GSI, Darmstadt, Germany \\ ${ }^{\S}$ Institute of Nuclear Research, Debrecen, Hungary \\ "Laboratoire de Physique Corpusculaire, Caen, France \\ "Università degli studi e INFN sezione di Milano, Italy \\ ${ }^{\dagger \dagger}$ IFIN-HH, Bucharest-Magurele, Romania \\ $\ddagger$ GANIL, Caen, France \\ ${ }^{\S}$ Nuclear Physics Institute of ASCR, $\breve{R} e \breve{z}$, Czech Republic

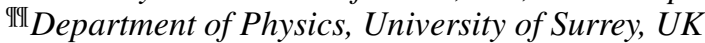 \\ ${ }^{* * *}$ Niels Bohr Institute, University of Copenhagen, Denmark
}

\begin{abstract}
An experiment was performed to extend the knowledge of excited states in neutrondeficient $\mathrm{Ca}$ isotopes. In particular, excited states in ${ }^{36} \mathrm{Ca}$ were searched for to allow for a comparison with its stable mirror nucleus, ${ }^{36} \mathrm{~S}$. Secondary beams of ${ }^{37} \mathrm{Ca}$ and ${ }^{36} \mathrm{Ca}$ were produced by fragmentation of a primary ${ }^{40} \mathrm{Ca}$ beam with an energy of $95 \cdot A \mathrm{MeV}$ on the SISSI target at GANIL. A variety of nuclei around ${ }^{36} \mathrm{Ca}$ has been produced in a secondary Be target by neutron and protonremoval at beam energies around $61 \cdot A \mathrm{MeV}$. The produced nuclei were identified using the spectrometer SPEG, and prompt $\gamma$ rays were measured with the Château de Cristal. A preliminary value for the energy of the first $2^{+}$state of ${ }^{36} \mathrm{Ca}$ has been determined.
\end{abstract}

Keywords: ${ }^{36} \mathrm{Ca}$,neutron removal reaction,mirror nuclei,Coulomb displacement energy

PACS: 21.10.-k, 23.20.Lv, 27.30+t

In recent years, the isospin dependence of the nucleon-nucleon interaction has attracted much interest both from theory [1] and, since exotic beams become more and more available, from experimental works. The present experiment aimed to measure the excitation energy of the first $2^{+}$state in ${ }^{36} \mathrm{Ca}$ and compare it to its mirror nucleus ${ }^{36} \mathrm{~S}$. In the ground state of ${ }^{36} \mathrm{~S}$, the $\pi d_{5 / 2}$ and $s_{1 / 2}$ as well as the $v d_{3 / 2}$ orbitals are completely filled. (In ${ }^{36} \mathrm{Ca}$, the same orbitals are occupied but by exchanging neutron and proton shells.) Due to the tensor interaction between the proton spin-orbit partners $d_{5 / 2}$ and $d_{3 / 2}$ and the neutron $d_{3 / 2}$ orbital, the proton $d_{5 / 2}$ orbital becomes more bound whereas the $\pi d_{3 / 2}$ becomes less bound than for nuclei where the $v d_{3 / 2}$ shell is incompletely filled. This subsequently enlarges the gaps between the $\pi s_{1 / 2}$ and $\pi d_{3 / 2}$ orbits on one hand 
and between the $\pi s_{1 / 2}$ and $\pi d_{5 / 2}$ orbits on the other hand, as illustrated by fig. 1 . This

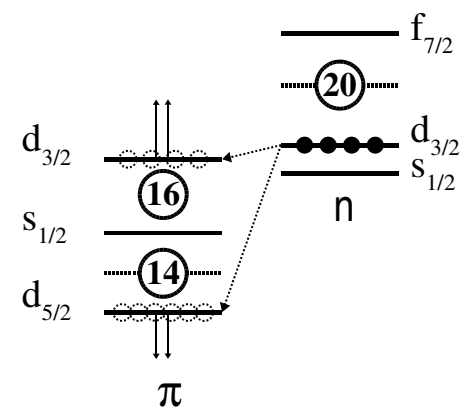

FIGURE 1. Illustration of the effect of the filled $v d_{3 / 2}$ in ${ }^{36} \mathrm{~S}$.

leads to high excitation energies for the first $2^{+}$state in both ${ }^{36} \mathrm{~S}$ and ${ }^{34} \mathrm{Si}$, which from this point of view reflects a spherical rigidity comparable to the doubly magic nucleus ${ }^{40} \mathrm{Ca}$. In the mirror nucleus of ${ }^{36} \mathrm{~S},{ }^{36} \mathrm{Ca}$, the same picture should apply with protons and neutrons exchanged, so that also in this case a high excitation energy can be expected for the $2^{+}$state. The primary aim of the experiment was thus to measure the excitation energy of the first $2^{+}$state in ${ }^{36} \mathrm{Ca}$ and compare it to the known one in its mirror nucleus.

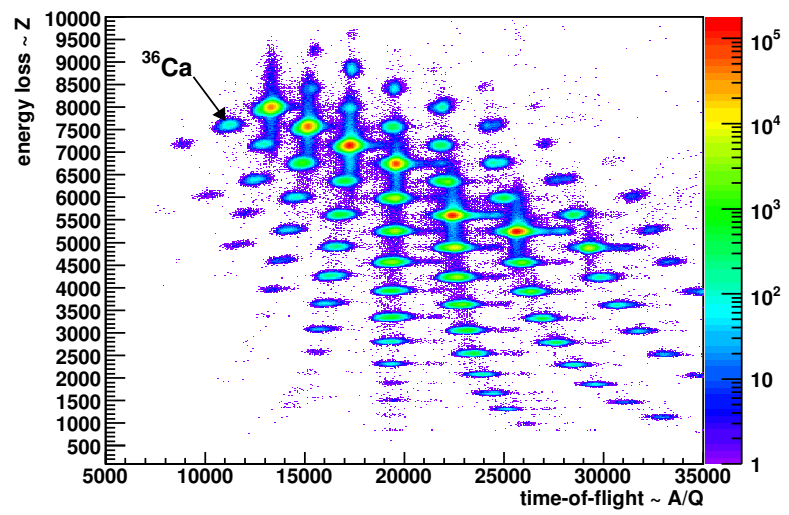

FIGURE 2. Particle identification using the SPEG ionisation chamber and time-of-flight.

The experiment was performed at the GANIL in Caen, France. The primary ${ }^{40} \mathrm{Ca}$ beam of $95 \cdot A \mathrm{MeV}$ was fragmented in the SISSI target. The resulting beam cocktail was purified in the " $\alpha$ " spectrometer consisting of two dipole magnets and a degrader which was optimised for ${ }^{37} \mathrm{Ca}$. The fragments were identified event by event through a time-offlight measurement between the " $\alpha$ " spectrometer and the secondary ${ }^{9}$ Be target of $1 \mathrm{~mm}$ thickness, in which further nucleons are removed at an energy of around $61 \cdot A \mathrm{MeV}$. After passing through the target, the produced fragments were selected and identified by the SPEG spectrometer through time-of-flight and energy loss measurements. For the present analysis, only the particle identification after the secondary target has been used. The quality of this identification is excellent as can be seen from fig. 2. To measure the $\gamma$-ray energies, the Château de Cristal, an array of $74 \mathrm{BaF}_{2}$ detectors, was placed around the Be target. In addition, three Ge clover detectors from the EXOGAM array were used, but their signals have not yet been evaluated. The calibration of the $\mathrm{BaF}_{2}$ detectors was 
performed using source data and some well-separated and sufficiently intense known transitions in nuclei produced in the secondary target. Example spectra for four nuclei are shown in fig. 3. The velocity used for the Doppler correction of the energies was

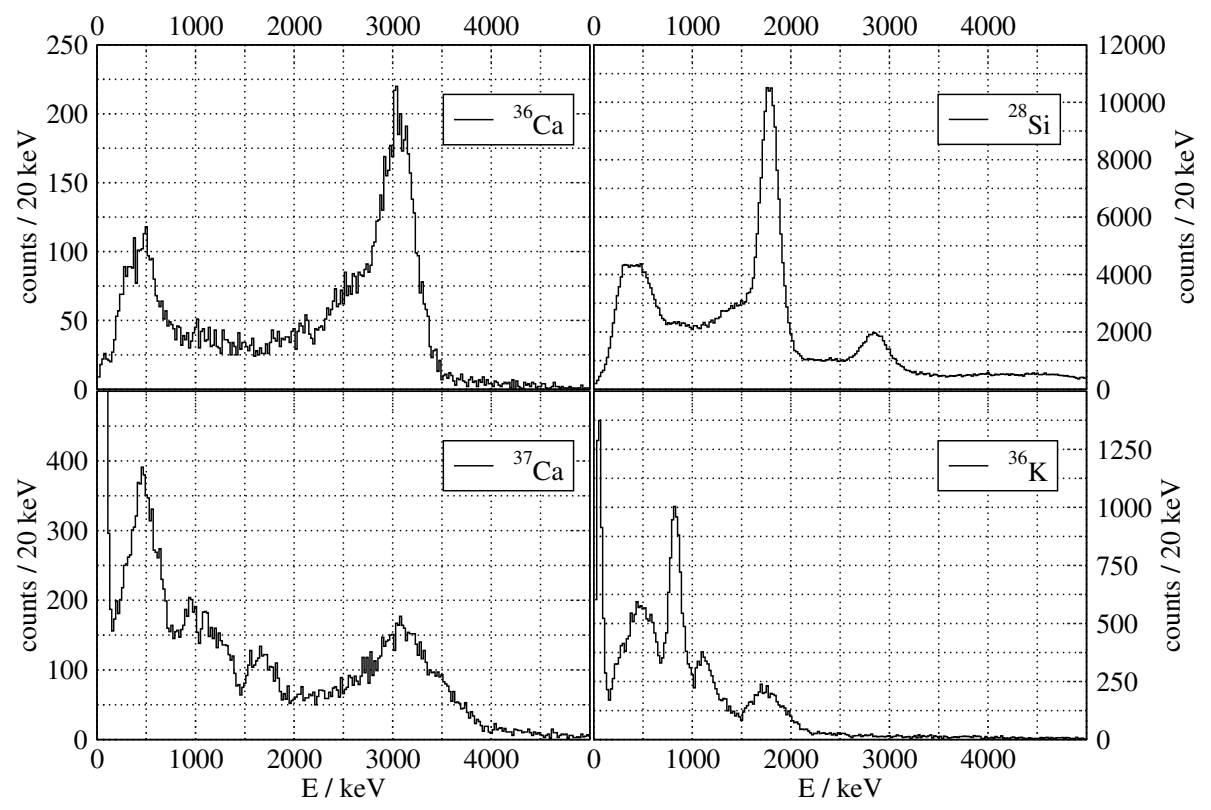

FIGURE 3. Example spectra for the four nuclei ${ }^{36} \mathrm{Ca},{ }^{28} \mathrm{Si}$ (which has been used for calibration), ${ }^{37} \mathrm{Ca}$ and ${ }^{36} \mathrm{~K}$.

calculated assuming that the nucleon removal takes place in the middle of the secondary target and taking into account the different half-lives of the nuclear states, if known. For the presented ${ }^{36} \mathrm{Ca}$ spectrum, the half-life of the $2^{+}$state was assumed to be the same as in the mirror nucleus ${ }^{36} \mathrm{~S}$, and the corresponding velocity was also used for the ${ }^{37} \mathrm{Ca}$ and ${ }^{36} \mathrm{~K}$ spectra. The energy of the $2^{+}$state in ${ }^{36} \mathrm{Ca}$ has been determined to be $E\left(2^{+}\right)=3050(60) \mathrm{keV}$.

As the result is preliminary and the error value is still large, an extensive discussion is only possible after some further progress of the analysis. Nevertheless, the present value is around $240 \mathrm{keV}$ lower than the $E\left(2^{+}\right)$in the mirror nucleus, ${ }^{36} \mathrm{~S}$, which is more than expected. This is, with ${ }^{14} \mathrm{C}-{ }^{14} \mathrm{O}$, one of largest mirror energy differences observed so far for the first excited $2^{+}$state. This could be due to the Coulomb energy difference between a pure $s$ and a pure $d$ configuration involved in the $2^{+}$state of ${ }^{36} \mathrm{~S}$, as a pronounced single particle character is expected due to the large $\mathrm{Z}=16$ gap. On the other hand, the $2^{+}$state in ${ }^{36} \mathrm{Ca}$ is well above the proton-separation threshold (around $500 \mathrm{keV}$ ), and the coupling to the continuum is also expected to have an influence on the $2^{+}$state in ${ }^{36} \mathrm{Ca}$. It can already be pointed out that the relatively low excitation energy of the $2^{+}$state in ${ }^{36} \mathrm{Ca}$ can affect the proton capture cross section by orders of magnitude, with important consequences for astrophysics.

\section{REFERENCES}

1. T. Otsuka et al., Acta Phys. Pol. B 36, 1213 (2005). 